\title{
Relationship between Maxillary Sinus Hypoplasia and Maxillary Occlusal Cant: A Cone Beam CT Study
}

\author{
Noura A. Alsufyani $\mathbb{D}^{1,2}$ Michael P. Major, ${ }^{2}$ and Paul W. Major $\mathbb{D D}^{2}$ \\ ${ }^{1}$ Oral Medicine and Diagnostic Sciences, College of Dentistry, King Saud University, Riyadh, Saudi Arabia \\ ${ }^{2}$ School of Dentistry, Faculty of Medicine and Dentistry, University of Alberta, Edmonton, AB, Canada \\ Correspondence should be addressed to Noura A. Alsufyani; alsufyan@ualberta.ca
}

Received 11 November 2021; Revised 12 January 2022; Accepted 3 February 2022; Published 18 February 2022

Academic Editor: Riccardo Nucera

Copyright (c) 2022 Noura A. Alsufyani et al. This is an open access article distributed under the Creative Commons Attribution License, which permits unrestricted use, distribution, and reproduction in any medium, provided the original work is properly cited.

\begin{abstract}
Introduction. Maxillary sinus hypoplasia (MSH) has been reported to cause a cant in the orbital plane. No similar reports exist about the possible impact on the maxilla. The aim of this study was to assess if MSH is associated with maxillary occlusal plane (MOP) cant and if dental or mandibular factors influenced the existence of the MOP cant. Methods. 80 cone beam CT images of subjects with MSH were analyzed for the type of $\mathrm{MSH}$, degree of MOP cant, open or cross bite, mandibular asymmetry, and degenerative joint disease of the temporomandibular joints. The subjects were compared with a control group matched by age and gender. Results. The degree of MOP cant (range $0-5.1^{\circ}$ ) was not statistically significantly different in unilateral vs. bilateral $\mathrm{MSH}$ or between the different types of MSH. The frequency of open bite, crossbite, mandibular asymmetry, or degenerative joint disease in unilateral vs. bilateral MSH or between the different types of MSH was not statistically significantly different. Between the case and control, there was no statistically significant difference in the degree of MOP cant $\left(1.3 \pm 1.1^{\circ}\right.$ vs. $1.1 \pm 0.9^{\circ}$, respectively) or frequency of dental and mandibular factors. There was low positive linear correlation between MOP cant and mandibular symmetry in MSH subjects (Spearman's rho = 0.23) and controls (Spearman's rho $=0.187)$. Conclusions. The data suggests a view of the alveolar bone as the adaptable skeletal unit to ensure and bridge the functionality between the nasomaxillary complex and TMJ system-two systems with very different function, and therefore largely independent "matrix units."
\end{abstract}

\section{Introduction}

The maxillary sinus is one of the four paranasal sinuses that are air-filled extensions of the nasal cavity. The maxillary sinus reaches final pneumatization inferiorly with the eruption of maxillary teeth by the age of 15-18 years [1]. At a prevalence of $1.5-10 \%$, the process by which abnormal pneumatization would cause maxillary sinus hypoplasia (MSH) is not known and poorly described [2-4].

The presence of MSH has been shown to cause asymmetries in its superior and medial neighbors, the orbit and nasal cavity, respectively $[2,3,5-7]$. Inferior positioning of orbital floor or bowing of the lateral wall of the nasal cavity ipsilateral to the MSH has been documented [8]. Canting of the orbital floor was even proposed as an added feature to classify MSH [7].

From the third week of intrauterine life until 18 years of age, the craniofacial complex growth is affected by genetic and complex external and internal environmental factors which guide or alter the pattern of growth $[9,10]$. The developmental complexity is understandable given the coexistence of dental structures, temporomandibular joints, osseous and soft tissues of the maxilla, mandible, and cranial base.

Asymmetries of the inferior neighbor, i.e., the alveolar process of maxilla, due to MSH have not been thoroughly studied. Selcuk et al. [11] found that $25.8 \%$ of MSH was associated with elevation of the canine fossa. Out of 495 clinical asymmetry patients, $36 \%$ of asymmetries were found in 
TABLE 1: The difference in MOP cant and dental and mandibular factors among MSH factors within MSH subjects $(n=80)$.

\begin{tabular}{|c|c|c|c|c|c|c|c|}
\hline & $\begin{array}{c}\text { Unilateral } \\
66(82.5 \%)\end{array}$ & $\begin{array}{c}\text { Bilateral } \\
14(17.5 \%)\end{array}$ & $P$ value & $\begin{array}{c}\text { Type I } \\
56(70 \%)\end{array}$ & $\begin{array}{c}\text { Type II } \\
20(25 \%)\end{array}$ & $\begin{array}{c}\text { Type III } \\
4(5 \%)\end{array}$ & $P$ value \\
\hline $\begin{array}{l}\text { MOP cant } \\
\text { Mean } \pm \mathrm{SD}^{\circ} \\
\text { (range) }\end{array}$ & $\begin{array}{c}1.32 \pm 1.2 \\
(0-5.1)\end{array}$ & $\begin{array}{c}1.25 \pm 0.92 \\
(0.2-3.1)\end{array}$ & $0.80^{*}$ & $\begin{array}{l}1.2 \pm 1 \\
(0-5.1)\end{array}$ & $\begin{array}{l}1.7 \pm 1.4 \\
(0-5)\end{array}$ & $\begin{array}{c}1.1 \pm 1.7 \\
(0-3.7)\end{array}$ & $0.21^{*}$ \\
\hline $\begin{array}{l}\text { Mandibular asymmetry }>5 \mathrm{~mm} \\
N(\%)\end{array}$ & $16(20 \%)$ & 0 & $0.06^{\ddagger}$ & $11(13.8 \%)$ & $5(6.3 \%)$ & 0 & $0.5^{\neq}$ \\
\hline $\begin{array}{l}\text { TMJ-DJD } \\
N(\%)\end{array}$ & $19(23.8 \%)$ & $2(2.5 \%)$ & $0.26^{\mathrm{I}}$ & $15(18.8 \%)$ & $6(7.5 \%)$ & 0 & $0.4^{\neq}$ \\
\hline $\begin{array}{l}\text { Open bite } \\
N(\%)\end{array}$ & $11(13.8 \%)$ & $1(1.3 \%)$ & $0.36^{\mathrm{I}}$ & $6(7.5 \%)$ & $4(5.0 \%)$ & $2(2.5 \%)$ & $0.08^{\mathrm{I}}$ \\
\hline $\begin{array}{l}\text { Cross bite } \\
N(\%)\end{array}$ & $7(8.8 \%)$ & $2(2.5 \%)$ & $0.69^{\mathrm{I}}$ & $5(6.3 \%)$ & $4(5.0 \%)$ & 0 & $0.3^{\neq}$ \\
\hline
\end{tabular}

${ }^{*}$ Kruskal-Wallis test. ${ }^{\mathrm{I}}$ Chi-squared test. ${ }^{\ddagger}$ Fisher's exact test. TMJ-DJD: temporomandibular joint-degenerative joint disease.

TABLE 2: The difference in MOP cant and dental and mandibular factors between MSH subjects and their controls.

\begin{tabular}{|c|c|c|c|}
\hline & Case $n=80$ & Control $n=80$ & $P$ value \\
\hline $\begin{array}{l}\text { MOP cant } \\
\text { Mean } \pm \mathrm{SD}^{\circ} \\
\text { (range) }\end{array}$ & $\begin{array}{c}1.3 \pm 1.1 \\
(0-5.1)\end{array}$ & $\begin{array}{c}1.1 \pm 0.9 \\
(0-4.2)\end{array}$ & $0.58^{*}$ \\
\hline $\begin{array}{l}\text { Mandibular asymmetry } \\
\text { Mean } \pm \text { SD mm } \\
\text { (range) }\end{array}$ & $\begin{array}{c}1.6 \pm 1.7 \\
(0-7)\end{array}$ & $\begin{array}{c}1.5 \pm 1.7 \\
(0-6.4)\end{array}$ & $0.90^{*}$ \\
\hline $\begin{array}{l}\text { TMJ-DJD } \\
N(\%)\end{array}$ & $\begin{array}{l}\text { Absent } 59(73.8 \%) \\
\text { Present } 21(26.3 \%)\end{array}$ & $\begin{array}{l}\text { Absent } 63(78.8 \%) \\
\text { Present } 17(21.3 \%)\end{array}$ & $0.61^{\ddagger}$ \\
\hline $\begin{array}{l}\text { Open bite } \\
N(\%)\end{array}$ & $\begin{array}{l}\text { Absent } 68(85 \%) \\
\text { Present } 12(15 \%)\end{array}$ & $\begin{array}{c}\text { Absent } 71(88.8 \%) \\
\text { Present } 9(11.3 \%)\end{array}$ & $0.65^{\neq}$ \\
\hline $\begin{array}{l}\text { Crossbite } \\
N(\%)\end{array}$ & $\begin{array}{c}\text { Absent } 71(88.8 \%) \\
\text { Present } 9(11.3 \%)\end{array}$ & $\begin{array}{c}\text { Absent } 79(98.8 \%) \\
\text { Present } 1(1.3 \%)\end{array}$ & $0.88^{\neq}$ \\
\hline
\end{tabular}

${ }^{*}$ Wilcoxon signed-rank test. ${ }^{\mathrm{I}} \mathrm{Chi}$-squared test. ${ }^{*}$ McNemar test. TMJ-DJD: temporomandibular joint-degenerative joint disease.

the midface and $74 \%$ were in the chin [10]. However, there are no studies highlighting the possible association of $\mathrm{MSH}$ with dentoalveolar cant of the maxilla, mandibular, or TMJ asymmetry.

In the presence of MSH, would an asymmetry in the alveolar process of the ipsilateral maxilla exist? If so, would the mandible also show an asymmetry?

The primary objective of this study was to assess whether $\mathrm{MSH}$ is associated with maxillary occlusal plane (MOP) cant. Secondary objectives were to assess if dental or mandibular factors influenced the existence of the maxillary occlusal plane cant.

\section{Materials and Methods}

2.1. Cone Beam CT Data. The study received approval (Pro00089618) from the Health Research Ethics BoardHealth Panel, University of Alberta. It was based on the retrospective maxillofacial CBCT images that included the maxillary sinuses and was used in a previous study analyzing $\mathrm{MSH}$ and associated nasal anomalies [8]. The sample consisted of 80 subjects with $\mathrm{MSH}$ and 80 matched controls (total $n=160$ ). There were 100 females and 60 males, and the mean age was $36.3 \pm 13.4$ years.

The CBCT scans for the MSH and control groups included subjects previously referred to dental imaging clinic to rule out pathology in the TMJs. The exclusion criteria were as follows: subjects younger than 18 (to ensure full development of maxillary sinus), edentulous jaws (to eliminate sampling bias due to sinus pneumatization), incomplete image of the maxillary sinuses, poor scan quality or motion artifact, evident history of trauma or surgery to the maxilla or maxillary sinuses, and congenital disease or syndrome affecting the maxillofacial complex.

All CBCT analyses were conducted using InVivoDental Viewer [version 6.0.5., Anatomage, San Jose, CA].

To standardize the orientation of the CBCT volume, the following planes were used:

$X$ plane: using the axial image sections, the $R$ and $L$ porion were aligned such that the horizontal plane $(X)$ passes through both. This was considered the 0 (horizontal or floor) plane. This corrected for right-left head rotation.

$Z$ plane: using the sagittal image sections, the right porion and orbitale were aligned to become parallel to the 0 plane, bilaterally. This corrected for superior-inferior head tilt. 


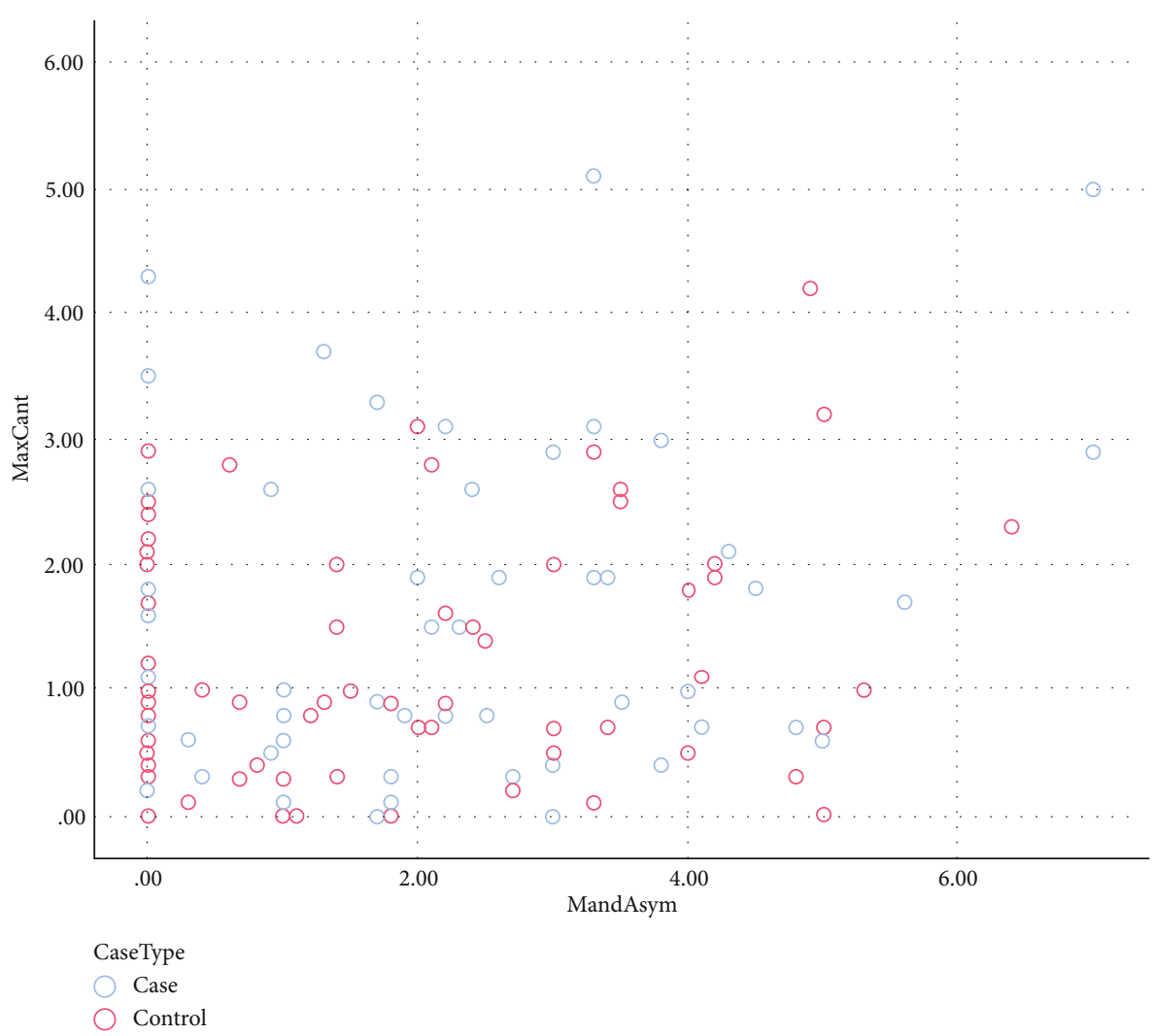

FIGURE 1: Scatter plot of linear correlation between mandibular asymmetry $(\mathrm{mm})$ and MOP cant $\left(^{\circ}\right)$.

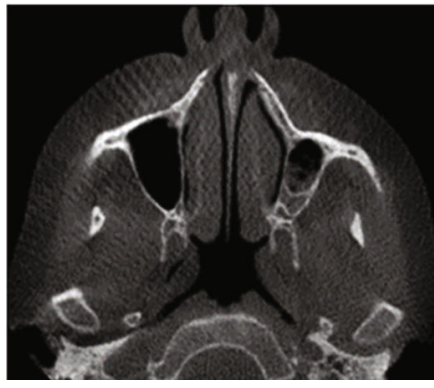

(a)

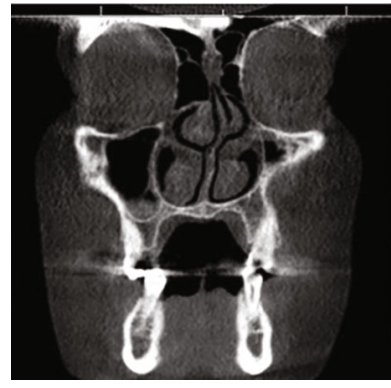

(b)

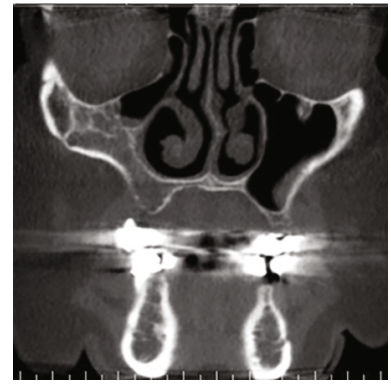

(c)

FIGURE 2: MSH type III with 0-degree maxillary occlusal plane cant. (a) Axial and (b) coronal cone beam CT images of left MSH (same subject) showing symmetry of premolars on the occlusal plane. (c) Coronal cone beam CT image of right MSH showing well-formed alveolar process irrespective of the sinus hypoplasia.

$Y$ plane: using the coronal image sections, the midsagittal plane was identified by a line bisecting crista galli and frontonasal suture, then aligned to be perpendicular to the $X$ and $Z$ planes determined above. This corrected for sideto-side head tilt.

2.2. MSH Analysis. The classification of MSH by Bolger et al. [2] was used by the principal investigator (oral and maxillofacial radiologist) by primarily assessing the coronal section, confirmed by axial and sagittal sections, and comparing right and left sides. Two variables were collected:

(1) Unilateral vs. bilateral MSH

(2) MSH types [2]: (i) Type I: mild hypoplasia, normal uncinated process, and a patent infundibular tract

(ii) Type II: sinus hypoplasia, hypoplastic uncinated process, and an ill-defined or absent infundibular passage

(iii) Type III: characterized by profound sinus hypoplasia, "cleft-like," and an absent uncinated process

2.3. MOP Cant Analysis. Intermolar line connecting the buccal most point of the furcation between the mesiobuccal and distobuccal roots of \#16 (right maxillary first molar) and \#26 


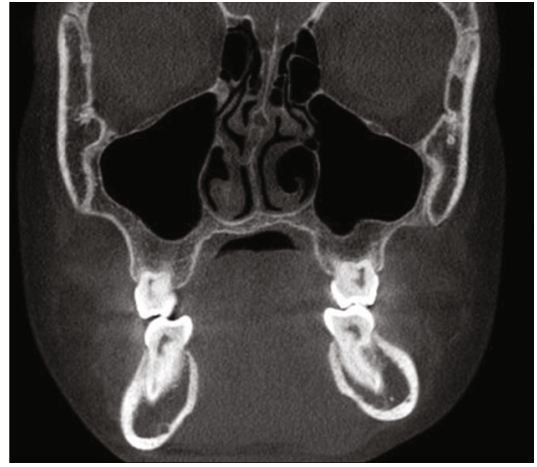

(a)

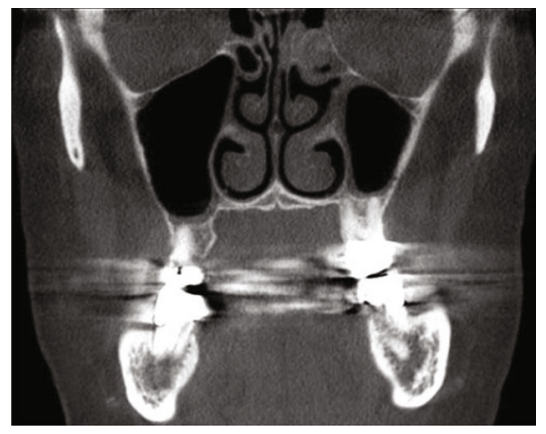

(c)

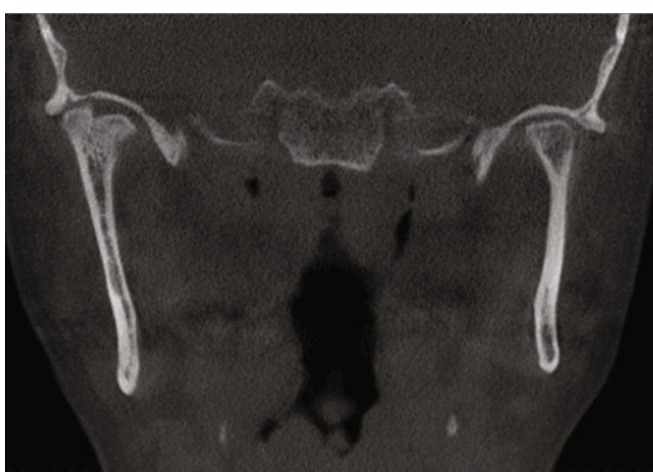

(b)

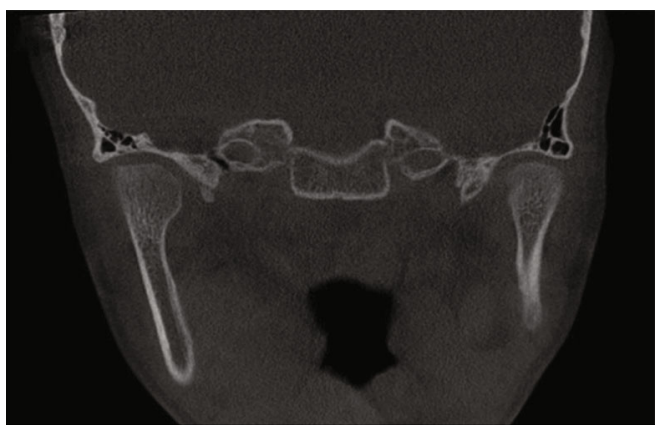

(d)

Figure 3: Large maxillary occlusal plane cant over $4^{\circ}$. Coronal cone beam CT images of $(a, b)$ control case and (c, d) MSH case, showing left condylar hypoplasia.

(left maxillary first molar). If either molar was missing, the maxillary second molar was used (\#17 or \#27).

Zero cant is when the angle formed between the intermolar line and midsagittal plane is $90^{\circ}$. Any deviation is measured as possible cant. Using five cases (not included in this study), intraexaminer reliability in identifying furcation points and MOP cant were measured three times, one week apart by the PI. The reliability was measured by intraclass correlation coefficient ICC and the random error of reliability was measured using Dahlberg's formula:

$$
D=\sqrt{\sum_{i=1}^{N} \frac{d_{i}^{2}}{2 N}}
$$

where $d_{i}$ is the difference between the paired measurements, and $N$ is the sample size.

The maximum error in $\mathrm{mm}$ at cutoff of 3 pixels $=1.2$ $\mathrm{mm}$.

2.4. Dental and Mandibular Analysis. The following are the dental and mandibular variables:

(1) Mandibular asymmetry: subjectively recorded as present/absent and objectively measured as the distance $(\mathrm{mm})$ of lingual foramen to the midsagittal plane on the $\mathrm{x}$ axis.

(2) Anterior open bite: present/absent

(3) Crossbite: present/absent
(4) Degenerative joint disease: present/absent

2.5. Statistical Analysis. To adequately assess the possible association of MSH with MOP cant and dental and mandibular factors, a control group, i.e., subjects without maxillary sinus hypoplasia, matched for age and gender were analyzed for the same variables.

To assess the differences in MOP cant among the MSH, dental and mandibular variables, chi-squared or Fisher's exact, and Kruskal-Wallis tests were used for categorical and numerical data, respectively.

To assess differences in MOP cant among the dental and mandibular variables between $\mathrm{MSH}$ subjects and their matched controls, McNemar or Fisher's exact tests were used for categorical data and Wilcoxon signed-rank test for numerical data. Linear correlation between MOP cant and mandibular asymmetry was tested using Spearman rho, in both groups. SPSS (version 25.0, IBM Corp., Armonk, New York, USA) was used for all tests.

\section{Results}

The intraexaminer reliability was excellent for marking the maxillary furcation for the right and left maxillary molar (ICC range $0.97-100)$. For the $X, Y$, and $Z$ coordinates for maxillary furcation, the mean difference in measurements ranged from 0.08 to $0.20 \mathrm{~mm}$ with maximum examiner error from 0.10 to $0.65 \mathrm{~mm}$. The random error ranged from 0.05 to $0.3 \mathrm{~mm}$. The reported errors did not exceed the cutoff $(1.2 \mathrm{~mm})$. The intraexaminer reliability was excellent (ICC 
0.90 ) for MOP cant with a mean error of $0.4 \pm 0.2^{\circ}$, a maximum error of $0.8^{\circ}$, and a random error of $0.2-0.5^{\circ}$.

Based on the large standard deviations and Shapiro-Wilk test $(P<0.0001)$, the normality was rejected and nonparametric tests were used.

Within the MSH group, most were unilateral (82.5\%) and type I (70\%). The degree of MOP cant was not statistically significantly different in unilateral vs. bilateral $\mathrm{MSH}$ or between the different types of MSH (type I, II, or III hypoplasia) (Table 1). The frequency of open bite, crossbite, mandibular asymmetry, or degenerative joint disease in unilateral vs. bilateral MSH or between the different types of MSH was not statistically significantly different (Table 1).

Between the MSH subjects and their matching controls (total $n=160$ ), there was no statistically significant difference in the frequency of dental and mandibular factors (Table 2). There was nonsignificant or low positive linear correlation between MOP cant and mandibular symmetry in MSH subjects (Spearman's rho $=0.23, P$ value 0.04 ) and controls (Spearman's rho $=0.187, P$ value 0.09) (Figure 1).

\section{Discussion}

The method used to assess the MOP cant was similar to the work done by Kheir and Kau [9] and was found to be reliable with clinically acceptable measurement error, less than $1 \mathrm{~mm}$.

In the MSH group, the sinus hypoplasia was mostly unilateral and mild (type I). Although the population represents subjects referred to rule out pathology in the TMJs, degenerative joint disease was found in only $21(26.3 \%)$. Similarly, mandibular and dental factors were not commonly present: mandibular asymmetry $16(20 \%)$, open bite $12(15 \%)$, and crossbite nine $(11.3 \%)$. Their frequency was not statistically significant neither between unilateral and bilateral $\mathrm{MSH}$ nor between the different types of MSH. As such, mandibular asymmetry, open bite, and crossbite were not considered possible covariates for the analysis of MOP cant. The mean MOP cant was small, not exceeding $2^{\circ}$, across all types of MSH as well as unilateral versus bilateral MSH. The maximum MOP cant was $5.1^{\circ}$. Padwa et al. found that cants greater than $4^{\circ}$ were detected clinically by both untrained and trained observers [12]. Olivares et al. [13] agree with this finding and furthermore showed that although orthodontists had better detection for occlusal cant of $2^{\circ}$ compared to general dentists and laypersons, all examiners evaluated them as aesthetically acceptable. Thus, although some occlusal cants within the MSH group can be detected clinically, their existence was not affected by the fact that the MSH was unilateral or severe, for example.

In the control group, the extent of mandibular asymmetry and the presence of TMJ-DJD, open bite, and crossbite were not statistically significantly different than the MSH group and were not a common occurrence. Moreover, the linear relationship between mandibular asymmetry in $\mathrm{mm}$ and MOP cant was very low and not significant. As such, mandibular asymmetry, open bite, and crossbite were not considered possible covariates for the analysis of MOP cant. The mean MOP cant was not statistically significantly differ- ent between the MSH group and their matched controls. In both groups, the mean MOP cant did not exceed $2^{\circ}$.

Although there are reports of canine fossa elevation in cases with $\mathrm{MSH}$, the possible impact on dental occlusal plane was not assessed $[11,14]$.

If MSH was found to alter the position of the inferior orbital wall and lateral wall of nasal cavity, why was not such impact significant in the alveolar process of maxilla? There are two unique facts about the inferior neighbor of the maxillary sinus, the TMJs and teeth. Based on Moss' functional matrix theory, the development and change in size, shape, and position of the skeletal unit respond to the morphogenetic primary demand of the nonskeletal tissues, i.e., the functional matrices [15]. As such, the development of the TMJ is largely dictated by the surrounding nonskeletal tissues, mainly muscles, to reach a state of equilibrium and to ensure that the osseous tissues are not under pressure [16]. To maintain the joint in a musculoskeletally stable position, the TMJs influence the position of posterior and anterior teeth. The role of posterior teeth is to maintain vertical dimension of occlusion, and the anterior teeth are crucial for anterior guidance (movement) of the mandible [16, 17]. The location of teeth during eruption and posteruption is also largely guided by buccal and lingual muscular forces, from tongue and cheeks. Therefore, the functional matrix, i.e., muscles and teeth, influences how the TMJs, alveolar process of maxilla, and mandible respond [16-18].

In addition to Moss' theory, Wolff's law explains that remodeling of bone responds to loading. Cyclic loading exists in the maxilla and mandible through the occlusal forces generated and maintained by the teeth, so the metabolism of bone adapts to the loads exerted by teeth [19]. Collectively, the functional demands and physiologic response described by Moss and Wolff may explain why the maxilla and MOP did not significantly cant in the presence of MSH.

An example is shown in Figure 2, a type III (severe) MSH with evident depression in the anterior wall of sinus; however, the left maxillary premolar maintains the occlusal plane symmetry, and the underlying alveolar process is well-formed due to the occlusal forces exerted by the posterior maxillary teeth and as such did not follow the MSH.

Although MOP cant did not show strong correlation with mandibular deviation or TM-DJD, cases with a more significant MOP cant ( $4.2^{\circ}$ in control case and $5^{\circ}$ in MSH case) demonstrated unilateral condylar hypoplasia (Figure 3). This may indicate condyle growth has a larger influence on occlusal cant than MSH.

Taking into consideration the complex factors, larger sample size and advanced 3D analysis of the mandible would be needed to test such influence. However, the data suggests a view of the alveolar bone as the adaptable skeletal unit to ensure and bridge the functionality between the nasomaxillary complex and TMJ system-two systems with very different function, and therefore largely independent "matrix units." The high degree of plasticity of alveolar bone demonstrated during orthodontic treatment is a strong piece of collaborative evidence.

The main shortcoming of this study is the small effect size of occlusal cant to reach a power $>0.80$ given the sample 
size, as it is based on a previous study. The complexity of craniofacial-mandibular growth would require larger sample size to allow for robust statistical analyses. Threedimensional analysis of the osseous and dental structures would also be required to better measure changes rather than linear and angular measures.

In conclusion, the presence of MSH did not statistically significantly cause a cant in the MOP and was not associated with mandibular asymmetry, open bite, or crossbite. These findings suggest the alveolar complex is able to functionally compensate for a diminished volume of underlying maxillary basal bone caused by MSH. Instead, the influence of the TMJs, the cyclic forces exerted by mastication, the need for functional occlusion, and the maintenance of musculoskeletal stability may surpass the influence of maxillary sinus size on lower face development including the occlusal plane.

\section{Data Availability}

Data are available on request by contacting the corresponding author.

\section{Disclosure}

An earlier version of it has been presented as a preprint [8, 20].

\section{Conflicts of Interest}

The authors declare no conflict of interest.

\section{Acknowledgment}

An earlier version of it has been presented as a preprint (Alsufyani et al., [20]).

\section{References}

[1] J. S. Daniels, I. Ali, I. M. Al Bakri, and B. Sumangala, "Pleomorphic adenoma of the palate in children and adolescents: a report of 2 cases and review of the literature," Journal of Oral and Maxillofacial Surgery, vol. 65, no. 3, pp. 541-549, 2007.

[2] W. E. Bolger, W. W. Woodruff Jr., J. Morehead, and D. S. Parsons, "Maxillary sinus hypoplasia: classification and description of associated uncinate process hypoplasia," Otolaryngology - Head and Neck Surgery, vol. 103, no. 5, pp. 759-765, 1990.

[3] D. L. Price and O. Friedman, "Facial asymmetry in maxillary sinus hypoplasia," International Journal of Pediatric Otorhinolaryngology, vol. 71, no. 10, pp. 1627-1630, 2007.

[4] J. M. Sánchez Fernández, J. A. Anta Escuredo, A. Sánchez Del Rey, and F. Santaolalla Montoya, "Morphometric study of the paranasal sinuses in normal and pathological conditions," Acta Oto-Laryngologica, vol. 120, no. 2, pp. 273-278, 2000.

[5] M. Wake, L. Shankar, M. Hawke, and S. Takeno, "Maxillary sinus hypoplasia, embryology, and radiology," Archives of Otolaryngology-Head and Neck Surgery, vol. 119, no. 12, pp. 1353-1357, 1993.

[6] T. Erdem, D. Aktas, G. Erdem, M. C. Mimam, and O. Ozturan, "Maxillary sinus hypoplasia," Rhinology, vol. 40, no. 3, pp. 150-153, 2002.
[7] A. Sirikçi, Y. Bayazit, E. Gumusburun, M. Bayram, and M. Kanlikana, "A new approach to the classification of maxillary sinus hypoplasia with relevant clinical implications," Surgical and Radiologic Anatomy, vol. 22, no. 5-6, pp. 243-247, 2001.

[8] N. Alsufyani, H. El-Hakim, and P. Major, "Prevalence of maxillary sinus hypoplasia and association with variations in the sinonasal complex: a cone beam CT study," Clinical Oral Investigations, vol. 25, no. 9, pp. 5463-5471, 2021.

[9] N. A. Kheir and C. H. Kau, "The use of three-dimensional imaging to evaluate the effect of conventional orthodontic approach in treating a subject with facial asymmetry," Annals of Maxillofacial Surgery, vol. 6, no. 1, pp. 105-112, 2016.

[10] T. R. Severt and W. R. Proffit, "The prevalence of facial asymmetry in the dentofacial deformities population at the university of North Carolina," The International Journal of Adult Orthodontics and Orthognathic Surgery, vol. 12, no. 3, pp. 171-176, 1997.

[11] A. Selcuk, K. M. Ozcan, O. Akdogan, N. Bilal, and H. Dere, "Variations of maxillary sinus and accompanying anatomical and pathological structures," The Journal of Craniofacial Surgery, vol. 19, no. 1, pp. 159-164, 2008.

[12] B. L. Padwa, M. O. Kaiser, and L. B. Kaban, "Occlusal cant in the frontal plane as a reflection of facial asymmetry," Journal of Oral and Maxillofacial Surgery, vol. 55, no. 8, pp. 811-816, 1997.

[13] A. Olivares, A. Vicente, C. Jacobo, S. M. Molina, A. Rodríguez, and L. A. Bravo, "Canting of the occlusal plane: perceptions of dental professionals and laypersons," Medicina Oral, Patologia Oral Y Cirugia Bucal, vol. 18, no. 3, pp. e516-e520, 2013.

[14] J. J. Geraghty and K. D. Dolan, "Computed tomography of the hypoplastic maxillary sinus," The Annals of Otology, Rhinology, and Laryngology, vol. 98, no. 11, pp. 916-918, 1989.

[15] M. L. Moss, "The functional matrix hypothesis revisited. 1. The role of mechanotransduction," American Journal of Orthodontics and Dentofacial Orthopedics, vol. 112, no. 1, pp. 8-11, 1997.

[16] J. Okeson, Management of Temporomandibular Disorders and Occlusion, Elsevier Mosby, St. Louis, Missouri, 8th edition, 2019.

[17] A. Björk and V. Skieller, "Facial development and tooth eruption: an implant study at the age of puberty," American Journal of Orthodontics, vol. 62, no. 4, pp. 339-383, 1972.

[18] M. L. Moss and L. Salentijn, "The primary role of functional matrices in facial growth," American Journal of Orthodontics, vol. 55, no. 6, pp. 566-577, 1969.

[19] H. M. Frost, “A 2003 update of bone physiology and Wolff's law for clinicians," The Angle Orthodontist, vol. 74, no. 1, pp. 3-15, 2004.

[20] N. Alsufyani, M. Major, and P. Major, Relationship between maxillary sinus hypoplasia and maxillary occlusal cant: a cone beam CT study, Research Square Pre-print, 2021. 